\title{
Dynamics in Self-Regulation: Plan Execution Self-Efficacy and Mastery of Action Plans
}

\author{
URTE SCHOLZ ${ }^{1}$ \\ University of Zurich \\ Zurich, Switzerland
}

\author{
FALKo F. SNIEHOTTA \\ Health Psychology \\ University of Aberdeen \\ and \\ Aberdeen Centre for Energy Regulation \\ and Obesity (ACERO) \\ Aberdeen, Scotland, UK
}

\author{
Benjamin SchÜZ and Andries Oeberst \\ Jacobs University Bremen \\ Bremen, Germany
}

\begin{abstract}
This study investigated whether an individual's plan execution self-efficacy precedes mastery of the respective action plan or vice versa. Study participants were 122 cardiac rehabilitation patients. Plan execution self-efficacy and mastery of a personal action plan on physical activity were assessed each week for 6 weeks after discharge from rehabilitation. Physical exercise was assessed 2 months after discharge. Multilevel cross-lagged panel analyses resulted in a positive effect of mastery on subsequent self-efficacy, whereas self-efficacy did not predict subsequent mastery at the within-person level. At the between-person level, however, self-efficacy predicted following physical exercise. Thus, the predictive power of self-efficacy was developed in relation to mastery of personal action plans over time. Implications for behavior change interventions are discussed.
\end{abstract}

Changing one's behavior is a difficult endeavor. Most people have experienced that one's best intentions (e.g., eat in a healthier manner, be more physically active, stop smoking) rarely translate into behavior. The prevalence of failure to act on one's intentions is supported by numerous studies and meta-analyses (e.g., Godin \& Kok, 1996; Sheeran, 2002).

There is compelling evidence of considerable discrepancies between people's intentions and their subsequent behavior. For example, Sheeran demonstrated in his meta-analysis that intentions explain only about $20-30 \%$ of behavior: a phenomenon known as intention-behavior gap. Prevailing theories in health behavior research, such as the theory of planned behavior

'Correspondence concerning this article should be addressed to Urte Scholz, University of Zurich, Department of Psychology, Social and Health Psychology, Binzmühlestrasse 14/Box 14, CH-8050, Zurich, Switzerland.E-mail: urte.scholz@psychologie.uzh.ch 
(Ajzen, 1991), provide a satisfying prediction of behavioral intentions. However, good intentions are hardly sufficient to predict behavior change. Thus, research should focus on identifying factors that help to translate one's intentions into behavior.

Social cognitive theory (SCT) assumes that self-efficacy beliefs play a crucial role in behavior change (Bandura, 1997). Self-efficacy refers to individuals' confidence in their ability to successfully perform a particular task (Bandura, 1977). High self-efficacy is theorized to facilitate the process of behavior change at two points: the formation of behavioral intentions, and the translation of intentions into behavior. Numerous studies have found evidence for these effects (cf. Bandura \& Locke, 2003).

Another factor that has proven to foster the implementation of intentions into behavior is action planning (Gollwitzer, 1999; Leventhal, Singer, \& Jones, 1965). Individuals who plan in detail when, where, and how to act are more likely to act on their intentions (i.e., implementation intentions; Gollwitzer \& Sheeran, 2006). This is the first study to examine the role that specific self-efficacy beliefs play in the execution of action plans.

\section{Self-Efficacy and Behavior Change}

According to SCT, mastery experience (i.e., completing a task successfully) and self-efficacy influence each other reciprocally (Bandura, 1986, 1997). The experience of mastering a task enhances self-efficacy if this mastery is attributed to the actor's own competences. In turn, higher selfefficacy is assumed to facilitate mastery, which again might lead to an increase in self-efficacy. Via this process, perceived self-efficacy is shaped by experiences and reflects to some degree actual competence. For example, in smoking-cessation studies, self-efficacy has been found to be more predictive of cessation after a few weeks of experience with cessation attempts than initially without experience (e.g., Kok, De Vries, Mudde, \& Strecher, 1991; Mudde, Kok, \& Strecher, 1995). The mutual relationship between behavior and self-efficacy has also been demonstrated in the domain of physical activity (e.g., Dzewaltowski, 1994; Sallis, Hovell, Hofstetter, \& Barrington, 1992). Moreover, some studies suggest positive causal effects of self-efficacy on subsequent behavior change by applying cross-lagged panel designs (e.g., Evon \& Burns, 2004).

If the relationship between self-efficacy and behavior is studied at the within-person level, however, the results might point in the opposite direction. Vancouver and colleagues (Vancouver, Thompson, Tischner, \& Putka, 2002; Vancouver, Thompson, \& Williams, 2001) found negative effects of self-efficacy on performance of a computer game at the within-person level. 


\section{8}

The authors explained these contradictory findings with the aggregation bias that might occur when running analyses at the between-person level: Positive relationships between self-efficacy and performance at the between-person level (i.e., persons with higher self-efficacy also report higher levels of performance than persons with lower self-efficacy) might result from interindividual differences in actual ability (Vancouver et al., 2002). At the withinperson level; however, higher self-efficacy of an individual at Time $t$ might result in lower performance at Time $t+1$ (e.g., as a result of overconfidence in one's abilities). The bias is a result of greater variability between persons than within persons. Thus, negative within-person relations might aggregate to positive between-person relations. To control for this source of erroneous interpretation of self-efficacy/mastery relations, within-person analyses are needed in order to draw the right conclusions for interventions.

Previous research has conceptualized self-efficacy predominantly as a nomothetical construct. According to Nagel (1961), nomothetical scientific approaches "seek to establish abstract general laws for indefinitely repeatable events and processes" (p. 547). Thus, all participants are asked to respond to the same items; for example "I am certain that I can exercise 3 times a week for at least 30 minutes." However, SCT theorizes about individual cognitions and, therefore, requests an idiothetic (Vancouver et al., 2001) research strategy. Idiothetic means taking into account the idiographic nature of personal goals and plans, but analyzing their associations within a nomothetical scientific framework. From the perspective of SCT (Bandura, 1997), therefore, action plans (Gollwitzer, 1999; Leventhal et al., 1965) can be conceptualized as highly specific individual tasks that people have set for themselves. If persons formulate individually different tasks or plans for themselves in order to achieve a behavioral goal, they hold specific self-efficacy beliefs about their ability to achieve every single specific task (or plan) during this process of achievement.

\section{Action Planning and Behavior Change}

Action planning specifies when, where, and how to implement an intended behavior (Gollwitzer, 1999; Leventhal et al., 1965). It links goaldirected responses to the situational cues previously specified by scheduling when and where to act. Planning helps to identify relevant cues more easily and facilitates initiating the behavior because behavioral responses are already at hand (Gollwitzer \& Oettingen, 1998; Orbell \& Sheeran, 2000). The effectiveness of action planning has been demonstrated for different behaviors, such as writing an essay over the winter break (Gollwitzer \& Brandstätter, 1997), tetanus vaccination (Leventhal et al., 1965), breast self- 
examination (Luszczynska \& Schwarzer, 2003), physical activity in students (Milne, Orbell, \& Sheeran, 2002), and physical activity in rehabilitation patients (Lippke, Ziegelmann, \& Schwarzer, 2004; Sniehotta, Scholz, \& Schwarzer, 2005). All of these studies have emphasized the predictive power of action planning with regard to a target behavior over a certain time span. This is the first study to investigate the microprocesses between baseline and follow-up assessments.

\section{Action Plans and Self-Efficacy}

Following the microanalytic strategy suggested by Bandura (1977; Bandura \& Adams, 1977), the examination of associations between selfefficacy and a specific task requires high congruence between self-efficacy and the specific task or situation. This means that items to assess self-efficacy should precisely reflect the conditions of the specific task. According to Bandura and Adams, this makes it possible to obtain the "most precise index of the relationship" (p. 296) of two components.

The microanalytic strategy, therefore, requires a combination of nomothetical and idiothetic strategies. The assessment of self-efficacy requires a nomothetical format (i.e., with the same item and response format) at the most specific, individual level (i.e., individual self-generated tasks), thus making an idiothetic approach to the content indispensable (Vancouver et al., 2001). For example, Person A might form the action plan "Every Monday, when I come home from work, I will go running for 45 minutes," and Person B forms the action plan "Every Wednesday morning I will go swimming before having breakfast." These two plans differ between the two people and are thus individual. At the same time, both people can express how confident they are that they can implement their plans at a comparable scale level. Thus, this self-efficacy is not only very specific, but also idiothetic. It quantifies a person's belief in his or her ability to execute this personal action plan. In the present study, we will refer to this selfefficacy for the execution of action plans as plan execution self-efficacy (PESE).

Although action plans activate cognitive patterns that support plan execution (Gollwitzer, 1999), the implementation of plans in the target situation still can be impeded by conflictive behavioral tendencies (Betsch, Haberstroh, Molter, \& Glöckner, 2004). Thus, PESE regarding a personal action plan may play a crucial role with regard to mastery of this action plan. To our knowledge, this has not yet been the subject of empirical studies. Therefore, the present study investigates the underlying processes of mastery of a personal action plan and the role that PESE plays. 


\section{The Present Study}

The present study assesses PESE in an idiothetic way. The conditions for individuals' PESE are defined by their personal action plans for physical activity. Plan execution self-efficacy indicates persons' confidence in their ability to act exactly as specified in their personal action plans. Together with repeatedly assessed self-reported mastery and nonmastery of plans, this approach allows elucidating whether PESE is the antecedent or the consequence of mastery and nonmastery of individual action plans.

The context of the present study is cardiac rehabilitation because individuals undergoing rehabilitation after acute cardiac events need to urgently change their behavior. Most of the persons in cardiac rehabilitation are, in fact, highly motivated to change their lifestyles after discharge (e.g., Johnston, Johnston, Pollard, Kinmonth, \& Mant, 2004; Sniehotta et al., 2005), but nevertheless usually fail to do so. We focus on regular physical exercise, which is a core treatment goal in cardiac rehabilitation (Grundy, Pasternak, Greenland, Smith, \& Fuster, 1999).

There is strong evidence that regular physical exercise is related to lower mortality, lower cardiac relapse rates, and reduced symptoms after the manifestation of coronary heart disease (CHD; cf. Thompson et al., 2003). For example, Jolliffe et al. (2003) reported in a meta-analysis that exercise interventions led to a $31 \%$ reduction of total cardiac mortality in CHD patients who underwent a long-term supervised exercise-training program. Furthermore, self-efficacy beliefs have also been shown to play a crucial role in cardiac rehabilitation. For example, higher self-efficacy is related to better compliance with exercise programs in cardiac samples (Ewart, 1995; Scholz, Sniehotta \& Schwarzer, 2005; Woodgate, Brawley, \& Weston, 2005). This has been acknowledged by the American Association of Cardiovascular and Pulmonary Rehabilitation (AACVPR, 2004), which has included selfefficacy beliefs in guidelines for cardiac rehabilitation as a crucial target in the promotion of behavior change.

In Germany, cardiac rehabilitation is usually implemented on an inpatient basis. Patients stay 3 to 4 weeks in the rehabilitation center and undergo a comprehensive psychoeducational and somatic treatment. After discharge, persons are challenged to change their behavior on their own and maintain these changes at home. Thus, the first weeks after discharge are assumed to be crucial in terms of intra-individual dynamic processes that influence the implementation of lifestyle changes.

The aim of the present study is to investigate the relationship between PESE and mastery or nonmastery of personal action plans regarding physical exercise within the first 6 weeks after discharge from cardiac rehabilitation. 
Additionally, the predictive power of PESE and mastery and nonmastery of plans on change in physical exercise level is compared.

$$
\text { Method }
$$

\section{Sample and Procedure}

Participants of the present study were 122 CHD inpatients (101 male, 21 female) with the medical recommendation for regular physical exercise. Each participant gave informed consent and was provided with a personal code to match the data of the questionnaires in order to ensure anonymity. Participants were assured confidentiality of all personal data and were informed that participation in the study was voluntary and unpaid.

In general, patients stayed 3 weeks in the rehabilitation center. The first assessment (T1) was during the second week of participants' stay in the cardiac rehabilitation center. All participants took part in a planning intervention during the third week of rehabilitation. Assisted by trained interviewers, participants formulated an action plan for their physical exercise after discharge. Participants were asked to indicate their PESE for this plan.

During the first 6 weeks after their discharge, participants were sent weekly questionnaires (W1 to W6) with their action plans written at the top of the page. These weekly questionnaires assessed PESE, mastery (i.e., successful plan execution), and nonmastery (i.e., failure to execute the plan). The last follow-up (T2) was implemented 2 months after participants' discharge. All follow-up questionnaires were sent to the participants' homes, together with prepaid return envelopes.

Participants' mean age was 59 years $(S D=9.4)$ and ranged from 32 to 79 years. The majority of participants $(82.8 \%)$ were men. Most participants were married or living with a partner $(n=98 ; 80.3 \%), 11$ persons $(9.0 \%)$ were divorced, $6(4.9 \%)$ were single, $5(4.1 \%)$ were widowed, and 2 persons $(1.6 \%)$ did not specify their marital status. Only 16 persons $(13.1 \%)$ did not have any children. There were 35 participants $(28.7 \%$ ) who reported a maximum of 9 years of school education, 23 participants $(18.9 \%)$ had 10 years, $33(27.1 \%)$ had 12 years, $28(23.0 \%)$ had 13 years, and $3(2.5 \%)$ persons did not report their years of schooling. Approximately half of the sample was currently employed $(n=59 ; 48.4 \%)$.

\section{Measures}

Time 1 and Time 2 questionnaires. In the Time 1 and Time 2 questionnaires, past physical exercise and condition-specific strenuous exercise were assessed. 


\section{2}

Past physical exercise. For the assessment of past physical exercise, the International Physical Activity Questionnaire (Booth, 2000) was adapted to the special characteristics of a cardiac sample. There were five domains of physical exercise that were taken into consideration: (a) vigorous exercise (e.g., swimming); (b) fitness activities (e.g., gymnastics); (c) game sports (e.g., volleyball, tennis); (d) moderate exercise to train muscle strength; and (e) other prescribed exercises.

Participants were asked to indicate how often per week and how long (in minutes) per session they engaged, on average, in each domain during the last 4 weeks prior to their acute cardiac event. For each domain, the amount of exercise was computed by multiplying exercise days per week by minutes per exercise session. These five products were then aggregated to a sum score. The sample mean for past physical exercise was 64.52 min per week $(S D=13.13)$. The percentage of missing values was $1.9 \%$.

Strenuous exercise. To assess condition-specific strenuous exercise at T2, participants were first asked in how many sessions and how long per session they have engaged in the five aforementioned domains during the past 4 weeks. In a second step, participants indicated how many of these activities equaled the intensity of their exercise program in the rehabilitation center.

The final measure was obtained by multiplying exercise days by minutes per session and aggregating to a sum only those activity scores that participants indicated equaled the intensity of their exercise program in the rehabilitation center. This was done in order to ensure that no activities below the recommended intensity level were included in this strenuous exercise measure at $\mathrm{T} 2$. The mean of this measure was $123.88 \mathrm{~min}$ per week $(S D=128.23)$. The percentage of missing values was $9.0 \%$.

In the weekly questionnaires, participants' personal action plans were written at the top of the page. A sample for a participant's action plan is "Every night after having finished my housework, I will use the treadmill for half an hour." On the same page, mastery of the plan, nonmastery of the plan, and PESE were assessed.

For the assessment of mastery of the plan, persons were asked "How often did you act exactly as planned?" Likewise, for the assessment of nonmastery of the plan, persons were asked "How often did you fail to act on your plan?" Because many participants did not specify exactly how often they planned to be physically active, mastery and nonmastery are independent constructs and do not contain redundant information. ${ }^{2}$ This is reflected by cross-sectional correlations between mastery and nonmastery that range only between -.23 $(p<.01)$ and $-.38(p<.01)$. The inclusion of nonmastery enables us to look

\footnotetext{
${ }^{2}$ In addition, participants might have interpreted exercising over and above the planned amount as plan fulfillment. We thank an anonymous reviewer for this suggestion.
} 
Table 1

Means and Percentage of Missing Data for Plan Execution Self-Efficacy (PESE), Plan Mastery, and Plan Nonmastery

\begin{tabular}{|c|c|c|c|c|c|c|c|c|c|}
\hline & \multicolumn{3}{|c|}{ PESE } & \multicolumn{3}{|c|}{ Mastery } & \multicolumn{3}{|c|}{ Nonmastery } \\
\hline & $M$ & $S D$ & $\begin{array}{c}\% \\
\text { missing }\end{array}$ & $M$ & $S D$ & $\begin{array}{c}\% \\
\text { missing }\end{array}$ & $M$ & $S D$ & $\begin{array}{c}\% \\
\text { missing }\end{array}$ \\
\hline PI & 3.20 & 0.56 & 5.7 & & & & & & \\
\hline W1 & 3.30 & 0.70 & 23.0 & 3.01 & 2.78 & 9.0 & 1.76 & 2.34 & 15.6 \\
\hline W2 & 3.17 & 0.82 & 19.7 & 3.56 & 2.93 & 9.8 & 1.16 & 1.84 & 18.9 \\
\hline W3 & 3.20 & 0.81 & 21.3 & 3.53 & 2.59 & 9.8 & 0.99 & 1.69 & 18.0 \\
\hline W4 & 3.35 & 0.80 & 23.8 & 3.41 & 2.40 & 11.5 & 1.22 & 1.96 & 15.6 \\
\hline W5 & 3.20 & 0.91 & 20.5 & 3.56 & 2.56 & 11.5 & 0.92 & 1.86 & 14.8 \\
\hline W6 & 3.30 & 0.67 & 21.3 & 3.53 & 2.48 & 10.7 & 0.80 & 1.55 & 16.4 \\
\hline
\end{tabular}

Note. $\mathrm{PI}=$ planning intervention; $\mathrm{W} 1-\mathrm{W} 6=$ weekly questionnaires.

at differences in the associations between mastery and nonmastery with PESE.

Plan execution self-efficacy (PESE). For the assessment of PESE, participants were asked to respond to the item "I am confident that I will be able to act exactly as I planned." The item was rated on a 4-point Likert scale ranging from 1 (completely disagree) to 4 (completely agree). PESE was also assessed during the planning intervention for the newly formulated action plan. Means, standard deviations, and percentages of missing values of PESE, mastery, and nonmastery are displayed in Table 1.

\section{Data Analyses}

The data structure of the process analyses over the 6 weeks was hierarchical because observations were nested in persons. Therefore, we used multilevel modeling (Bryk \& Raudenbush, 1992; Raudenbush \& Bryk, 2002) for the process analyses of PESE, mastery, and nonmastery of plans, employing the HLM 5.05 program (Raudenbush \& Bryk, 2002).

Multilevel modeling allows us to obtain estimates for relationships between PESE, mastery, and nonmastery of plans for each individual. Furthermore, it allows us to test whether relationships between these variables differ between persons and, if so, to take these differences into account when 


\section{4}

testing the relationships for significance. Because we are interested in learning more about the potential causal direction of relationships between PESE and mastery and nonmastery of plans, cross-lagged models on the within-person level were specified.

We used two-level models: a within-person level (Level 1), and a betweenperson level (Level 2). The Level 1 model specified person-specific regressions between PESE and mastery and nonmastery of a plan. As mastery and nonmastery of a plan were assessed retrospectively and PESE was assessed prospectively, different cross-lagged models were specified. For predicting mastery and nonmastery of a plan, previous-week mastery, nonmastery, and $\mathrm{PESE}^{3}$ were included as predictors. For the cross-lagged prediction of PESE, previous-week PESE, ${ }^{4}$ and mastery and nonmastery of the concurrent week were included as predictors.

Thus, the Level 1 models for the prediction of PESE read as follows (mastery $=$ MAS; nonmastery $=$ NONMAS):

$$
\begin{gathered}
\text { PESE }_{w i}=a_{0 i}+a_{1 i} \text { PESE }_{w-l i}+a_{2 i} M \text { AS }_{w i}+q_{w i} \\
\text { PESE }_{w i}=a_{0 i}+a_{1 i} \text { PESE }_{w-1 i}+a_{2 i} \text { NONMAS }_{w i}+q_{w i}
\end{gathered}
$$

In addition, for the prediction of mastery and nonmastery of plans, the Level 1 models read as follows:

$$
\begin{aligned}
\text { MAS }_{w i} & =a_{0 i}+a_{1 i} \text { MAS }_{w-l i}+a_{2 i} \text { PESE }_{w-l i}+q_{w i} \\
\text { NONMAS }_{w i} & =a_{0 i}+a_{1 i} \text { NONMAS }_{w-1 i}+a_{2 i} \text { PESE }_{w-1 i}+q_{w i}
\end{aligned}
$$

$P E S E_{w i}$ is the PESE of Person $\mathrm{i}$ in Week w. PWSE $E_{w-1 i}$ is the PESE of Person $\mathrm{i}$ in Week $\mathrm{w}-1 . M A S_{w-1 \mathrm{i}}$ and $N O N M A S_{w-1 \mathrm{i}}$ are the mastery and nonmastery of a plan of Person i in the previous week assessed retrospectively. $M A S_{w i}$ and $N O N M A S_{w i}$ are the mastery and nonmastery of a plan of Person i in week w assessed retrospectively.

The term $a_{0 i}$ is the estimate of the average PESE of Person i across all weeks, and $q_{w i}$ is the deviation of Week w from Person i's average. The terms $\mathrm{a}_{1 \mathrm{i}}$ and $\mathrm{a}_{2 \mathrm{i}}$ are the slopes, that may vary over persons.

In multilevel models, the Level 1 coefficients are the criteria for the Level 2 regression equations. This means that the Level 1 coefficients are expressed as a function of a mean value and a deviation on Level 2. Thus, the Level 2 equations read as follows:

\footnotetext{
${ }^{3}$ Starting with the first assessment during the planning intervention.

${ }^{4}$ See Footnote 3 .
} 


$$
\begin{aligned}
& \mathrm{a} 0 \mathrm{i}=\mathrm{G} 0+\mathrm{e} 0 \mathrm{i} \\
& \mathrm{a} 1 \mathrm{i}=\mathrm{G} 1+\mathrm{e} 1 \mathrm{i} \\
& \mathrm{a} 2 \mathrm{i}=\mathrm{G} 2+\mathrm{e} 2 \mathrm{i}
\end{aligned}
$$

$G 0$ indicates the effect for the average person on an average week in the dependent variable on Level 1 , and $e 0 i$ indicates the individual deviation of this effect. The terms $G 1$ and $G 2$ refer to the effect of an average person of the predictors of the Level 1 dependent variable, whereas $e 1 i$ and $e 2 i$ indicate Person i's deviations of these average effects.

For testing whether PESE was a stronger predictor for change in physical exercise at $\mathrm{T} 2$ than mastery and nonmastery of plans, hierarchical regression analyses were conducted with SPSS 12 (2003). In the first step, the baseline measure of physical exercise was entered. In the second step, PESE, mastery, and nonmastery of the action plan assessed at the sixth weekly diary were entered in the regression equation.

\section{Treatment of Missing Values}

The complete deletion of cases with missing values is only appropriate when the missing pattern meets the assumption of missing completely at random (MCAR; Little \& Rubin, 2002). In most studies, the missing pattern instead is missing at random (MAR), which means that the probability of missing values depends on the observed values. Listwise deletion then would not be the appropriate method to handle missing data. Therefore, missing values were estimated using the multiple imputations method (Schafer \& Graham, 2002) employing NORM 2.03 (Schafer, 1999).

Multiple imputation (MI) generates multiple data sets. Each of these data sets is analyzed separately. Results are then integrated following a method suggested by Rubin (1987) to obtain overall estimates and standard errors. Unlike alternative single-imputation methods, MI has the advantage of reflecting the uncertainty of missing data by the between-imputation variance (Schafer \& Graham, 2002). For the present study, 10 databases were generated. Missing percentages for the variables of the weekly questionnaires are displayed in Table 1.

\section{Results}

All slope variances of the Level 1 variables were significant, except for the slope variances of PESE in the analyses predicting mastery and non- 


\section{6}

mastery. For the significant variances of the slopes, we examined whether there were significant cross-level interactions with the Level 2 variables of age, gender, and past physical exercise. This was not the case for any of these Level 2 variables, indicating that associations between PESE and mastery and nonmastery of plans were not moderated by the Level 2 variables examined here. The intraclass correlations (ICCs) were .51, .66, and .44 for PESE, mastery, and nonmastery, respectively, indicating more than one third of within-person variance in all variables.

\section{Cross-Lagged Analyses}

To test the temporal relationship between PESE and mastery and nonmastery of plan, we conducted cross-lagged analyses on the withinperson level, as described previously. The first analysis tested the effect of PESE (assessed the previous week, or w -1) on mastery of plan, controlling for previous week mastery of plan (i.e., w - 1). The results show that, as expected, previous-week mastery of plan was a highly significant predictor $(B=.67, S E=.04, p<.01)$. Previous-week PESE, however, had no significant effect on change in mastery of plan $(B=.09, S E=.11$, $p=.46)$.

The second analysis tested the effects of mastery during the last week on PESE, controlling for previous-week PESE. Previous-week PESE was significantly related to PESE in the succeeding week $(B=.37, S E=.08, p<.01)$. Mastery of plan also resulted in a significant effect on $\operatorname{PESE}(B=.08$, $S E=.02, p<.01)$.

Analyses of the temporal associations between PESE and nonmastery of plans show very similar results. Previous-week nonmastery of plans was a significant predictor of subsequent nonmastery of plans $(B=.31, S E=.05$, $p<.01)$. The effect of previous-week PESE, however, was not significant $(B=-.12, S E=.10, p=.25)$. When predicting PESE with nonmastery of plans and controlling for previous-week PESE, both predictors were significant (previous-week PESE: $B=.40, S E=.07, p<.01$; previous-week nonmastery: $B=-.10, S E=.02, p<.01)$. Thus, the results of both sets of analyses indicate that mastery of plans and nonmastery of plans were important predictors for the development of PESE, whereas PESE was neither significantly related to change in mastery nor in nonmastery of plans. Accordingly, the results indicate that mastery and nonmastery of plans preceded PESE in the causal ordering. Mastery experience predicted changes in self-efficacy, whereas self-efficacy did not predict changes in mastery. 


\section{Between-Person Associations With Physical Exercise at T2}

First, Pearson correlations between PESE, mastery, nonmastery over the 6 weeks, and T2 levels of strenuous exercise (in min) were conducted and are presented in Figure 1. The figure demonstrates that the correlations increased for all three measures over time, with PESE having the steepest increase in correlations with T2 exercise from the third to the fourth week, and then showing an almost stable height of relationship. Furthermore, from the fourth through the sixth week, PESE yielded the highest correlations, compared to those of mastery and nonmastery of plan with T2 exercise.

Second, hierarchical between-person regression analyses were conducted in order to compare the predictive validity of PESE, mastery of plans, and nonmastery of plans in the sixth week after discharge for the prediction of physical exercise. The first step of the regression analyses includes past physical exercise as the baseline measure of the criterion. The second step includes mastery of plan, nonmastery of plan, and PESE from the sixth week after discharge.

Past physical exercise was not significantly related to strenuous exercise. Mastery and nonmastery of plan also did not contribute significantly to the amount of explained variance in exercise at $\mathrm{T} 2$. This was despite the fact that mastery of plan was significantly correlated to strenuous exercise at T2

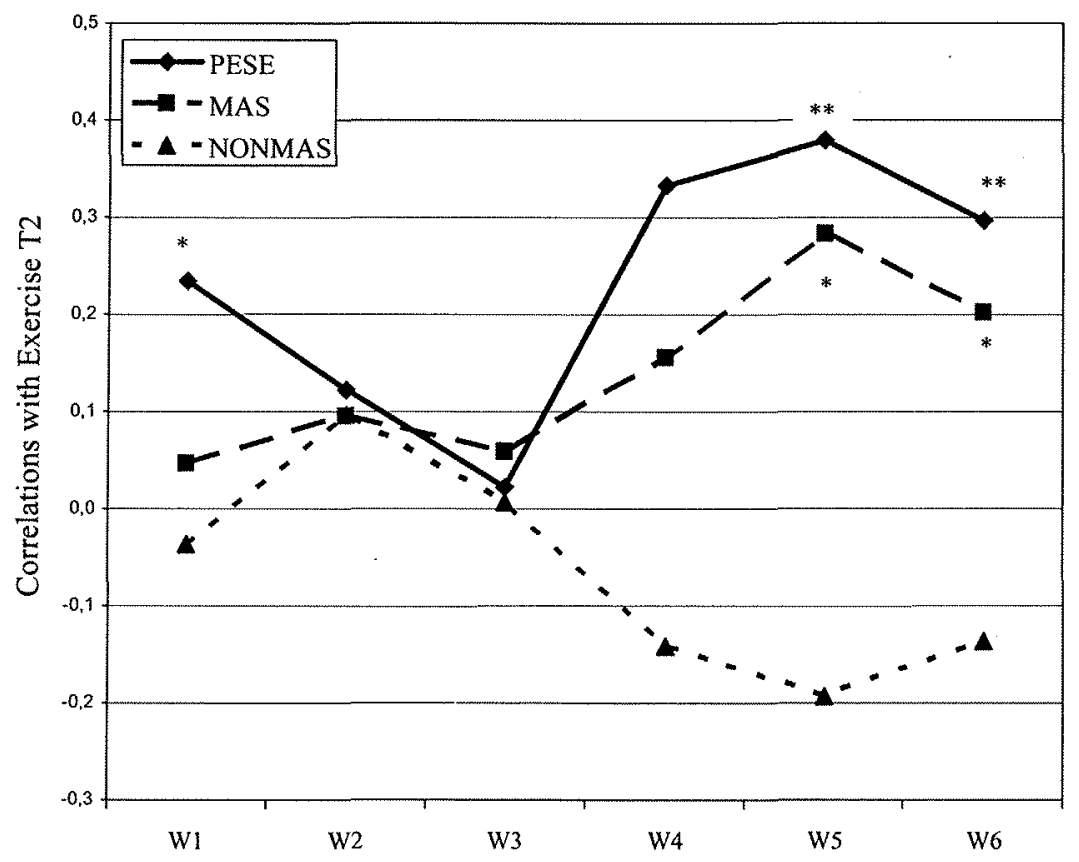

Figure 1. Correlations between plan execution self-efficacy (PESE), plan mastery (MAS), plan nonmastery (NONMAS), and strenuous exercise at Time 2 over the first 6 weeks after discharge. $* p<.05 . * * p<.001$. 


\section{8}

Table 2

Hierarchical Linear Regression of Strenuous Exercise at Time 2 on Past Physical Exercise, Mastery, Nonmastery, and PESE

\begin{tabular}{lcc}
\hline & $\beta$ Step 1 & $\beta$ Step 2 \\
\hline Past physical exercise at & .05 & .01 \\
$\quad$ Time 1 & & \\
Mastery at Week 6 & & .11 \\
Nonmastery at Week 6 & & .01 \\
PESE at Week 6 & & $.26^{*}$ \\
$R^{2}$ & .01 & $.11^{*}$ \\
\hline
\end{tabular}

Note. PESE $=$ plan execution self-efficacy.

$* p<.05$.

$(r=.20, p<.05)$. PESE remained the only significant predictor of strenuous exercise at T2 $(\beta=.26, p<.05)$. PESE thus can be identified as a more important predictor for change in physical exercise than mastery and nonmastery. All variables explained $11 \%$ of the variance in T2 strenuous exercise, with a significant change in explained variance of $10 \%$ in the second step. Regression weights are displayed in Table 2.

\section{Discussion}

The present study tested whether optimistic self-belief regarding the execution of a personal action plan would precede successful mastery of this plan in temporal and causal ordering, or whether this PESE developed over time by making experiences with plan mastery and nonmastery. Process analyses on the within-person level clearly speak in favor of the second option: Mastery and nonmastery of personal action plans seem to precede PESE in causal ordering.

\section{Exploring Dynamics in Self-Efficacy}

To date, there have been only a few studies that have conducted analyses of self-efficacy and behavior on the within-person level. To our knowl- 
edge, the present study is the first one in the domain of physical exercise. The results are similar to studies of other domains of behavior change. For example, Shiffman et al. (2000) found that the daily self-efficacy of smokers who quit did not predict the occurrence of a lapse after controlling for baseline self-efficacy. This indicates that within-person dynamics of self-efficacy did not influence subsequent behavior. After the first lapse, however, daily self-efficacy became predictive of complete relapse, even when controlling for stable between-person differences in self-efficacy. Postlapse self-efficacy predicted relapse, even if smoking behavior was controlled for.

SCT is a theory of individual behavior. The predominant use of betweenperson designs might result in misleading tests of central theoretical assumptions. Thus, idiographic or idiothetic analyses (i.e., at the within-person level) are of crucial importance in testing SCT's core assumptions, especially the reciprocal relationships between mastery and self-efficacy beliefs in the context of non-normatively synchronized behavioral tasks (e.g., action plans with weekly assessments of mastery). Therefore, the findings of the present study provide a different picture as compared to previous research. While mastery experience is crucial for the development of self-efficacy beliefs as supported by our data, we did not find a cross-lagged effect of self-efficacy on mastery or nonmastery on the within-person level. Thus, the assumption of reciprocity could not be confirmed on the within-person level during the first 6 weeks of the behavioral change process.

\section{Predictive Validity of Self-Efficacy}

The between-person analyses demonstrate that the predictive validity of PESE developed over time (see Figure 1). In the between-person regression analysis, PESE was the most important predictor of subsequent self-reported exercise. This allows for the conclusion that experience with a behavior calibrates persons' optimistic self-beliefs about the fulfillment of their own plans, which then in turn predicts change in behavior.

These results correspond with studies showing that mastery experience moderated the relationship between self-efficacy and behavior. Self-efficacy based on mastery experience was always more predictive for change of this particular behavior and its maintenance than was self-efficacy based on little or no experience (e.g., Kok et al., 1991; Mudde et al., 1995). By conducting within-person analyses during the first 6 weeks after discharge (i.e., at the beginning of the behavior change), the present study contributes to existing research by depicting the dynamics of mastery experience and self-efficacy for personal action plans regarding behavior change. 
Moreover, the findings of the between-person regression analysis emphasize that prediction does not equal causality. The best predictor of behavior does not need to be the cause of behavior. This provides another argument to the view that theories of behavior should not be tested predominantly in between-person correlational designs (Weinstein, in press).

The within-person approach used in this study also contributes to another line of research by providing important insight into the mechanisms of the positive effects of action planning on behavior. Following the results of the present study, mastery experience with a personal action plan provides the background for development of self-efficacy beliefs specific for this action plan and thus fosters goal attainment. Therefore, the present study contributes to the understanding of the positive effects that action plans have on behavior by applying this microanalytical perspective.

\section{Limitations}

Some limitations of this study must be acknowledged. First, the measures for mastery of plan, nonmastery of plan, and PESE were single-item measures. The idiographic nature of these measures may mitigate this limitation insofar as the high precision of the questions regarding a specific personal plan that was written just above the questions might allow participants to give very precise and specific answers. Second, the measure for physical activity was self-reported. Objective measures for physical activity would have been preferable to the self-report approach that we used. There is evidence, however, that self-report measures of physical exercise behavior are reasonably valid (e.g., Bernstein et al., 1998; Miller, Freedson, \& Kline, 1994).

Usually, there is a tradeoff between the level of specificity of a self-efficacy measure and its predictive power (Luszczynska \& Schwarzer, 2005). On the one hand, highly specific self-efficacy cognitions (as were used here) are assumed to show a stronger association with the corresponding behavior than are more general measures. The disadvantage of such a specific measure, however, is the narrow range of behaviors that it may predict (Ajzen, 1996). Thus, the amount of specificity is dependent on the research questions. In the present study, however, we not only demonstrated that mastery and nonmastery of a personal action plan were significantly related to PESE, but also that PESE was predictive of changes in more general exercise behavior. Thus, the results speak in favor of predictive validity because of and despite the high specificity of the measure.

Furthermore, conclusions about causality resulting from cross-lagged panel analyses must be drawn with appropriate caution because we cannot 
rule out by these analyses that there are also different explanations for the lack of an effect of PESE on mastery. One possibility is that the chosen time interval of one week was inappropriate for examining the effects of selfefficacy on mastery experience (e.g., an increase in self-efficacy might already have positive effects on mastery of behavior the next day). Another possibility is that although the multilevel approach chosen here controls for individual differences or stable situational differences, the influence of another time-varying third variable (e.g., self-monitoring) that was not measured in this study cannot be excluded as a possible explanation.

\section{Implications}

The results of the current study provide implications for interventions and for future research regarding planning and self-efficacy. They emphasize the importance of mastery experience for the development of valid self-efficacy cognitions. Thus, persons who intend to change their behavior should be advised to formulate realistic action plans in order to assure mastery experiences.

Future research should apply a design that would follow up not only the first 6 weeks of behavior change, but a longer time interval with weekly questionnaires to enable within-person analyses of an extended time period. Such a research design would not only avoid being affected by a possible aggregation bias, but also might be better able to detect the effects of selfefficacy on behavior later in the behavior change process on the microanalytical level; that is, after self-efficacy has been shaped by mastery experience.

\section{References}

Ajzen, I. (1991). The theory of planned behavior. Organizational Behavior and Human Decision Processes, 50, 179-211.

Ajzen, I. (1996). The directive influence of attitudes on behavior. In P. M. Gollwitzer \& J. A. Bargh (Eds.), The psychology of action: Linking cognition and motivation to behavior (pp. 385-403). New York: Guilford.

American Association of Cardiovascular and Pulmonary Rehabilitation Outcome Committee (AACVPR). (2004). Guidelines for cardiac rehabilitation and secondary prevention programs ( $4^{\text {th }}$ ed.). Champaign, IL: Human Kinetics.

Bandura, A. (1977). Self-efficacy. Toward a unifying theory of behavior change. Psychological Review, 84, 191-215. 
Bandura, A. (1986). Social foundations of thought and action: A social cognitive theory. Upper Saddle River, NJ: Prentice Hall.

Bandura, A. (1997). Self-efficacy: The exercise of control. New York: Freeman.

Bandura, A., \& Adams, N. E. (1977). Analysis of self-efficacy theory of behavioral change. Cognitive Therapy and Research, 1, 287-308.

Bandura, A., \& Locke, E. A. (2003). Negative self-efficacy and goal effects revisited. Journal of Applied Psychology, 88, 87-99.

Bernstein, M., Sloutskis, D., Kumanyika, S., Sparti, A., Schutz, Y., \& Morabia, A. (1998). Data-based approach for developing a physical activity frequency questionnaire. American Journal of Epidemiology, 147, 147156.

Betsch, T., Haberstroh, S., Molter, B., \& Glöckner, A. (2004). Oops, I did it again: Relapse errors in routinized decision making. Organizational Behavior and Human Decision Processes, 93, 62-74.

Booth, M. L. (2000). Assessment of physical activity: An international perspective. Research Quarterly for Exercise and Sport, 71, 114-120.

Bryk, A. S., \& Raudenbush, S. W. (1992). Hierarchical linear models. Newbury Park, CA: Sage.

Dzewaltowski, D. A. (1994). Physical activity determinants: A social cognitive approach. Medicine and Science in Sports and Exercise, 26, 13951399.

Evon, D. M., \& Burns, J. W. (2004). Process and outcome in cardiac rehabilitation: An examination of cross-lagged effects. Journal of Consulting and Clinical Psychology, 72, 605-616.

Ewart, C. K. (1995). Self-efficacy and recovery from heart attack: Implications for a social cognitive analysis of exercise and emotion. In J. E. Maddux (Ed.), Self-efficacy, adaptation, and adjustment: Theory, research, and application (pp. 203-226). New York: Plenum.

Godin, G., \& Kok, G. (1996). The theory of planned behavior: A review of its applications to health-related behaviors. American Journal of Health Promotion, 11, 87-97.

Gollwitzer, P. M. (1999). Implementation intentions: Strong effects of simple plans. American Psychologist, 54, 493-503.

Gollwitzer, P. M., \& Brandstätter, V. (1997). Implementation intentions and effective goal pursuit. Journal of Personality and Social Psychology, 73, 186-199.

Gollwitzer, P. M., \& Oettingen, G. (1998). The emergence and implementation of health goals. Psychology and Health, 13, 687-715.

Gollwitzer, P. M., \& Sheeran, P. (2006). Implementation intentions and goal achievement: A meta-analysis of effects and processes. Advances in Experimental Social Psychology, 38, 69-119. 
Grundy, S. M., Pasternak, R., Greenland, P., Smith, S., Jr., \& Fuster, V. (1999). Assessment of cardiovascular risk by use of multiple-risk-factor assessment equations: A statement of healthcare professionals from the American Heart Association and the American College of Cardiology. Circulation, 100, 1481-1492.

Johnston, D. W., Johnston, M., Pollard, B., Kinmonth, A. L., \& Mant, D. (2004). Motivation is not enough: Prediction of risk behavior following diagnosis of coronary heart disease from the theory of planned behavior. Health Psychology, 23, 533-538.

Jolliffe, J. A., Rees, K., Taylor, R. S., Thompson, D., Oldridge, N., \& Ebrahim, S. (2003). Exercise-based rehabilitation for coronary heart disease (Cochrane methodology review). In The Cochrane Library (Vol. 4). Chichester, UK: John Wiley \& Sons.

Kok, G., De Vries, H., Mudde, A. N., \& Strecher, V. J. (1991). Planned health education and the role of self-efficacy: Dutch research. Health Education Research, 6, 231-238.

Leventhal, H., Singer, R., \& Jones, S. (1965). Effects of fear and specificity of recommendation upon attitudes and behavior. Journal of Personality and Social Psychology, 2, 20-29.

Lippke, S., Ziegelmann, J. P., \& Schwarzer, R. (2004). Behavioral intentions and action plans promote physical exercise: A longitudinal study with orthopedic rehabilitation patients. Journal of Sport and Exercise Psychology, 26, 470-483.

Little, R. J. A., \& Rubin, D. B. (2002). Statistical analysis with missing data $\left(2^{\text {nd }}\right.$ ed.). Hoboken, NJ: Wiley.

Luszczynska, A., \& Schwarzer, R. (2003). Planning and self-efficacy in the adoption and maintenance of breast self-examination: A longitudinal study on self-regulatory cognitions. Psychology and Health, 18, 93-108.

Luszczynska, A., \& Schwarzer, R. (2005). Social cognitive theory. In M. Conner \& P. Norman (Eds.), Predicting health behaviour ( $2^{\text {nd }}$ ed., rev. ed., pp. 127-169). Buckingham, UK: Open University Press.

Miller, D. J., Freedson, P. S., \& Kline, G. M. (1994). Comparison of activity levels using the Caltrac accelerometer and five questionnaires. Medicine and Science in Sports and Exercise, 26, 376-382.

Milne, S., Orbell, S., \& Sheeran, P. (2002). Combining motivational and volitional interventions to promote exercise participation: Protection motivation theory and implementation intentions. British Journal of Health Psychology, 7, 163-184.

Mudde, A. N., Kok, G., \& Strecher, V. J. (1995). Self-efficacy as a predictor for the cessation of smoking: Methodological issues and implications for smoking cessation programs. Psychology and Health, 10, 353367. 
Nagel, E. (1961). The structure of science: Problems in the logic of scientific explanation. New York: Harcourt, Brace, \& World.

Orbell, S., \& Sheeran, P. (2000). Motivational and volitional processes in action initiation: A field study of the role of implementation intentions. Journal of Applied Social Psychology, 30, 780-797.

Raudenbush, S. W., \& Bryk, A. S. (2002). Hierarchical linear models: Applications and data analysis methods ( $2^{\text {nd }}$ ed.). Thousand Oaks, CA: Sage.

Rubin, D. B. (1987). Multiple imputation for nonresponse in surveys. New York: John Wiley \& Sons.

Sallis, J. F., Hovell, M. F., Hofstetter, C. R., \& Barrington, E. (1992). Explanation of vigorous physical activity during two years using social learning variables. Social Science and Medicine, 34, 25-32.

Schafer, J. L. (1999). NORM: Multiple imputation of incomplete multivariate data under a normal model (Version 2). Software for Windows 95/98/NT. Retrieved November 16, 2004, from http://www.stat.psu.edu/ jls/ misoftwa.html

Schafer, J. L., \& Graham, J. W. (2002). Missing data: Our view of the state of the art. Psychological Methods, 7, 147-177.

Scholz, U., Sniehotta, F. F., \& Schwarzer, R. (2005). Predicting physical exercise in cardiac rehabilitation: The role of phase-specific self-efficacy beliefs. Journal of Sport and Exercise Psychology, 27, 135-151.

Sheeran, P. (2002). Intention-behavior relations: A conceptual and empirical review. In M. Hewstone \& W. Stroebe (Eds.), European review of social psychology (Vol. 12, pp. 1-36). Chichester, UK: Wiley.

Shiffman, S., Balabanis, M. H., Paty, J. A., Engberg, J., Gwaltney, C. J., Liu, K. S., et al. (2000). Dynamic effects of self-efficacy on smoking lapse and relapse. Health Psychology, 19, 315-323.

Sniehotta, F. F., Scholz, U., \& Schwarzer, R. (2005). Bridging the intentionbehavior gap: Planning, self-efficacy, and action control in the adoption and maintenance of physical exercise. Psychology and Health, 20, 143160.

SPSS for Windows. (2003). Version 12.0.1. Chicago: SPSS, Inc.

Thompson, P. D., Buchner, D., Piña, M. D., Balady, G. J., Williams, M. A., Marcus, B. H., et al. (2003). Exercise and physical activity in the prevention and treatment of atherosclerotic cardiovascular disease. Circulation, 107, 3109-3116.

Vancouver, J. B., Thompson, C. M., Tischner, E. C., \& Putka, D. J. (2002). Two studies examining the negative effect of self-efficacy on performance. Journal of Applied Psychology, 87, 506-516.

Vancouver, J. B., Thompson, C. M., \& Williams, A. A. (2001). The changing signs in the relationships among self-efficacy, personal goals, and performance. Journal of Applied Psychology, 86, 605-620. 
Weinstein, N. D. (in press). Misleading tests of health behaviour theories. Health Psychology.

Woodgate, J., Brawley, L. R., \& Weston, Z. J. (2005). Maintenance cardiac rehabilitation exercise adherence: Effects of task and self-regulatory selfefficacy. Journal of Applied Social Psychology, 35, 183-197. 